\title{
A New Optimization Approach for a Home Health Care Problem
}

\author{
Daouia Aiane and Adnen El-Amraoui \\ Laboratoire PRISME \\ Université d'Orléans \\ Orléans - Bourges, France \\ daouia.aiane@utbm.fr \\ adnen.el-amraoui@univ-orleans.fr
}

\author{
Khaled Mesghouni \\ Laboratoire CRIStAL \\ Ecole Centrale de Lille (EC-Lille) \\ Villeneuve d'Ascq, France \\ Khaled.mesghouni@ec-lille.fr
}

\begin{abstract}
This paper deals with the home health care services. The home health care services are defined as a set of medical, paramedical and social services delivered to patients in their domicile rather than in hospital. In this paper, a new Mixed Integer Linear Programming (MILP) model is proposed to make a planning for a home health care problem. The model is optimizing routes and rosters for the health care staffs, while problem specific constraints are satisfied. This model integrates an original concept related to the human behavior (e.g. patient behavior). The MILP model is solved using the commercial optimization software Ilog-Cplex of IBM. Computational results on several benchmarks, generated from a real living-lab (GIS MADONAH) in Bourges (France), proved that the proposed model can solve real large-sized problems within acceptable computational time.
\end{abstract}

Keywords- Home health care problem, Planning, MILP model, Optimization, Human behavior

\section{INTRODUCTION}

The hospital system is facing several problems. Some of them are related to operating rooms management and planning [1], doctors and nursing schedules, care demands of hospitalization, pressure in the hospital when several patients arrived simultaneously (e.g. problems of management, resources availability) [2], durations of stays which are often unknown in advance, and so on.

However, in order to shorten the hospital stay times and improve access to care services, while the demand of hospitalization is still increasing, several alternatives to hospitalization were proposed over the past fifty years. One of these alternatives is the Home Health Care (HHC) structures. They consist on providing medical or paramedical services in the patient's home. The main factors of its appearance are:

- Economic factors, where the aim is to control costs, safe the quality of healthcare services and reduce the overcrowding of hospitals.

- Social factors, which are related to the increase in life expectancy, the aging population and the development of several chronic diseases.
The alternative of the HHC aims to reduce health costs and satisfy patient. This alternative is complex due to the integration of the patient's home in the supply chain of care, the diversity of its activities and the multitude of uncertainties which are related to the care process (i.e. demand, new state of patient, journey times, durations of care, and so on).

Over time, this area arouses the curiosity of several researchers in the field of industrial engineering and operations research. The HHC's problematics is dividing into two classes as proposed in [3]. These classes are organized around two categories of decision making, including decisions on the implementation of patient care and on organizational decisions. The decisions of organizational types have been divided into three different levels of decision [4]. The first level is strategic one, it defines the long-term decisions taken by the leaders of the institution. Other, it presents the objective of the HHC. The second one is tactical. It is defined by the decisions of the middle managers to do work for the strategic management decisions. The third one is operational. It traduces all the decisions on the personal organization, which are defined by the scheduling care planning activities, nursing visits, stock management...

Besides, on a set of existing models from literature, some researchers identified in [5] a set of characteristics related to resources, patients and criteria. First, the characteristics related to resources include the types of resources (doctor, nurse, physiotherapist, ...), the preferences of the patients, of resource breaks (e.g. lunch breaks), unavailability of resources (e.g. predetermined work schedule), the regular resources (regular care of a patient), the mode of transport (public transport, private car, bicycle, ...), the maximum workload, the qualification of resources and the contract type (full or parttime). Secondly, characteristics related to patients include the availability of patients (e.g. one or more visits per day), the level of dependence (e.g. patient in bed, wheelchair...), the order of activities and the synchronization of activities when one or more treatments require multiple resources.

This paper deals with Home Health Care (HHC) planning resources. The proposed approach consists in elaborating a Mixed Integer Linear Programming (MILP) model to find a 
daily schedule of home health care that minimizes the resources workday durations.

This paper is organized into five sections. After the introduction, section 2 is devoted to literature review on scheduling resources planning in HHC problems. Section 3, presents the MILP model. An illustrative example and some experimental results are given in section 4. Section 5, concludes the paper and presents some issues for future research.

\section{LITERATURE REVIEW}

In [3], Redjem propose a new classification of HHC problems. In his classification, he defined three classes of HHC problems: geographical partitioning and allocation of human resources ([6], [7], [8]), allocation and scheduling of resources tours ([9], [10], [11], [12], [13]), and scheduling of resources tours ([14], [15], [16]).

By analogy with vehicle routing problem with time window, B. Bachouch et al. [17] proposed a mixed integer linear programming model while specific constraints, such as availability of patients, resources lunch breaks of and number of visits of the same resource at the same patient, are considered. They aim to optimize the sum of the resources travelling times.

In the same context, Bräysy et al. [18] were interested on the planning of tours for delivery meal for patients hospitalized at home in a Finnish region and to solve their model, they used a "local search" heuristic.

Then, Redjem et al. [19] supposed that the horizon time of planning of resources tours is one day and optimize several criteria: the distances covered by the resources, wait times between visits from the same patient, while the order of visits for a patient is considered. Moreover, they suggested two approaches based on linear mixed integer programming approach to model their problem.

Gayraud et al. [21] propose a new mathematical formulation of the home care scheduling problem; they consider patients' level of dependence and the qualifications of resources. Their model is solved for a sample of small and medium sizes. In [5], the same authors used their previous model, removed the criterion about the dependence of patients and added new constraints related to the synchronization of activities.

Liu et al. [22] developed a model which aims to find a set of $k$ roads, of minimum cost to serve the demand, whose delivery drug to patients from the hospital pharmacy and pick up blood sample to the medical laboratory, the patient availability and the maximum capacity of the vehicles are considered as criterions.

Cappanera and Scutella [23] also provide an integer linear program. Their goal is to balance the workload of staff and reduce their waiting time between two consecutive visits. The considered planning horizon is a week. The authors addressed the concept of pattern in their model in order to plan multiple patients visits during the week. This can be reached by assigning one or more resources and other criteria, such as the compatibility with the patient's needs and qualification of the resources.

Thi Viet Ly and Montemanni [24] proposed a mixed linear model to find the best schedule, while minimizing costs related to violations of time windows for patients and overtaking of working hours of the nursing staff. They consider balancing the workload of staff.

However, Issaoui et al. [25] developed a multi-objective mixed integer programming mathematical model which deals are: the increase of patient satisfaction and the number of health interventions and the decrease of the care interventions costs. To solve their problem, the authors used a three phases approach.

Lanzarone et al. [26] developed an allocation model with robust cardinality-constraints which exploits the potential of a mathematical programming model without generating scenarios. This model has been tested in instances from an Italian home care structure and the authors evaluated its ability to reduce the costs of nursing time extensions.

En-Nahli et al. [27] have developed a daily tours planning of health personnel based on mixed linear programming model, ensuring patient satisfaction in controlling costs. They took into account the preferences related to patients, essential for making better decision.

Another class of models based on the scheduling problems of resources tours with the consideration of the uncertainties in the workload of staff and in the number of treated patients is presented by Koeleman et al. [28]. The authors handled the uncertainty in representing the entire system as a Markov chain. They developed a policy for admitting patients in the HHC structure. Moreover, they considered that the problem of assignment nurse-patient, continuity of care and the demand are uncertain. Then Lanzarone et al. [29] approached the home care scheduling problem with stochastic programming based on the generation of a large number of scenarios. This approach has proven to be limited even though they have provided an improvement in the quality of the assignments developed by the HHC in practice.

In this paper, we focus on the latter two classes presented by Redjem [3] and we propose a new MILP model integrating human behavior (i.e. the patient behavior). This model is presented in the following section.

\section{MODELLING THE HOME HEALTH CARE PROBLEM WITH SPECIFIC CONSTRAINTS}

The proposed model is an extension of the model of multiple travelling salesman problems with time windows $\mathrm{M}$ TSPTW. We consider a set $P$ of $i$ patients needing health care at home, $(i \in P)$ and a set $R$ of $k$ resources $(k \in R)$ afford health care at the patient home in a given time windows $\left[b_{i}, e_{i}\right]$. We introduce two fictive patients " $O$ ", " $A+1$ " which define the starting and the ending node of the HHC structure ( $A$ is the total number of patients). The duration of health care in these nodes is zero and their time windows represent the time of opening and closing of the HHC structure. 
Note 1: it is assumed here that the HHC structure is open $24 \mathrm{~h} / 24 \mathrm{~h}$ and $7 / 7 \mathrm{~d}$, as considered by the legal structures of HHC [30], (Thus: the parameters $e_{0}$ and $e_{A+1}$ are fixed to 24 while the parameters $b_{0}$ and $b_{A+1}$ are fixed to 0 ).

\section{A. Assumptions}

Without loss of generality, it is assumed here, that:

(A1) Resources are working in the same geographical area and can operate in the entire territory of the patients.

(A2) Each patient needs a set of services (e.g. care) and each services defined in a time windows.

(A3) Resources are working on full time.

(A4) Each resource starts and finishes its working day in HHC structure.

(A5) Each patient is unavailable at least for one time windows.

(A6) One day (24 hours) is the considered planning horizon.

\section{B. Parameters}

In the following section, will be used the following notation:
A
Number of patient who needs health care.
$R \quad$ Number of resources (nurses, doctors, physiotherapist,).
Assign $_{i k} \quad$ Assignment index. Assign $n_{i k}=1$ if the resource $k$ is assigned to the patient $i$ and 0 otherwise.
$\left[b_{i}, e_{i}\right] \quad$ Time windows for achieving all the needed care for the patient $i$. $\begin{array}{ll}d_{i j} & \text { Travel duration between the patient } i \text { and } \\ \text { patient } j .\end{array}$
$c_{i k} \quad$ Care duration of the resource $k$ for the patient $i$.
M High value.

unavailability $_{p i} \quad$ Start date of unavailability of the

dunavailability $_{p i} \quad$ Duration of the unavailability of

Maxunavailability Maximum number of unavailability.

\section{Decision variables}

The model decisions variables are defined as follows:

$x_{i j k} \quad$ Assignment decision variable, $x_{i j k}=1$ if the resource $k$ visits the patient $i$ before patient $j$, and 0 otherwise.

$y_{k r i} \quad$ Assignment decision variable. $y_{k r i}=1$, if the patient $i$ is visited by the resource $k$ before $r$, and 0 otherwise.

$v_{i p k} \quad$ Assignment variable. $v_{i p k}=1$, if the resource $k$ visits the patient $i$ after his $p^{t h}$ unavailability and 0 otherwise.

$z_{i k} \quad$ Start date of the care of the patient $i$ by the resource $k$.

\section{Formulation of the problem}

We made a mathematical model based on mixed linear programming for the organization of home health care activities.

The objective function of our formulation given as below is to minimize travel time of each resource until his return to depot of HHC structure.

Minimize $D=\sum_{k=1}^{R} z_{A+1, k}$

Subject to :

$\sum_{i=0}^{A} x_{i j k}=$ Assign $_{j k}, \forall j=\overline{1, A}, \forall k=\overline{1, R}$

$\sum_{j=1}^{A+1} x_{i j k}=$ Assign $_{i k}, \forall i=\overline{1, A}, \forall k=\overline{1, R}$

$\sum_{j=1}^{A} x_{0 j k}=1, \forall k=\overline{1, R}$

$\sum_{i=1}^{A} x_{i(A+1) k}=1, \forall k=\overline{1, R}$

$\sum_{\substack{i=0 \\ i \neq l}}^{A} x_{i l k}=\sum_{\substack{j=1 \\ j \neq l}}^{A+1} x_{l j k}, \forall l=\overline{1, A}, \forall k=\overline{1, R}$

$\sum_{r=1}^{R} y_{k r i} \leq \operatorname{Assign}_{i k}, \forall i=\overline{0, A+1}, \forall k=\overline{1, R}$

$\sum_{k=1}^{R} y_{k r i} \leq$ Assign $_{i r}, \forall i=\overline{0, A+1}, \forall r=\overline{1, R}$

$\sum_{r=1}^{R} \sum_{k=1}^{R} y_{k r i}=\sum_{k=1}^{R} A_{s s i g n}-1, \forall i=\overline{1, A}$

$y_{k k i}=0, \forall i=\overline{0, A+1}, \forall k=\overline{1, R}$

$y_{k r 0}=0, \forall k=\overline{1, R}, \forall r=\overline{1, R}$

$y_{k r(A+1)}=0, \forall k=\overline{1, R}, \forall r=\overline{1, R}$

$z_{0 k}=b_{0}, \forall k=\overline{1, R}$ 
$z_{i k} \geq b_{i}, \forall i=\overline{1, A}, \forall k=\overline{1, R}$

$z_{i k}+c_{i k} \leq e_{i}, \forall i=\overline{1, A}, \forall k=\overline{1, R}$

$z_{i k}=0$, if $A_{\text {ssign }}=0, \forall i=\overline{1, A}, \forall k=\overline{1, R}$

$z_{j k} \geq z_{i k}+c_{i k}+d_{i j}+\left(x_{i j k}-1\right) \cdot M$,

$\forall i=\overline{0, A}, \forall j=\overline{1, A+1}, \forall k=\overline{1, R}$

$z_{i r} \geq z_{i k}+d_{i j}+\left(1-y_{k r i}\right) \cdot M, \forall i, j=\overline{1, A}, \forall k, r=\overline{1, R}$

$z_{i k} \leq$ unavailability $_{p i}+c_{i k}+v_{i p k} \cdot M, \forall i=\overline{0, A}, \forall k=\overline{1, R}$,

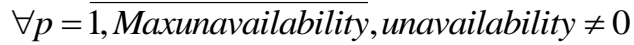

$z_{i k} \geq$ unavailability $_{p i}+$ dunavailability $_{p i}-d_{j i}+\left(v_{i p k}-1\right) \cdot M$,

$\forall i=\overline{0, A}, \forall j=\overline{1, A+1}, \forall k=\overline{1, R}$,

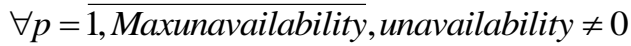

Constraints (2) and (3) ensure that each patient is visited by a number of requested resources for care delivery. Constraints (4) and (5) force the routes to start by the fictive activity " 0 " and finish by the fictive activity " $A+1$ ". The constraint (6) ensures the conservation of the flow. Constraints (7), (8) and (9) ensure that each resource has to visit all the patients that are assigned to it. Constraints (10), (11) and (12) make sure that the resource does not come twice in succession at the same patient; all resources start and finish their activities with the depot of HHC. Constraint (13) forces all resources to start their date of work with the depot, it represent the first time for the opening of the HHC structure. Constraints (14) and (15) assure that all activities are completed during the time window. Constraint (16) fixes to zero the start date care activity, when a patient is not assigned to a resource. Constraint (17) expresses the start date of care of resource $k$ at patient $j$ knowing that he arrive from patient $i$. Constraint (18) expresses the start date of care of resource $r$ at patient $i$ knowing that the resource $k$ has visited the patient $i$ just before him. Constraints (19) and (20) ensure that resources are passed before or after the patient's unavailability.

\section{COMPUTATIONAL RESUlTS}

This MILP model is solved using a commercial software ILOG-CPLEX Optimization studio of IBM, on Toshiba computer with Intel ${ }^{\circledR} \quad$ Core $^{\mathrm{TM}}$ i3-4012Y CPU@ microprocessor, a $1.50 \mathrm{GHz}$ frequency and a 4Go of memory.

In the following subsection, we propose to illustrate our approach with a simple example.

\section{A. Illustrative exemple}

In this example, we consider 5 patients $(P 1, P 2, P 3, P 4$, $P 5)$ suffering from different diseases. These patients require different cares and 5 different resources $(R 1, R 2, R 3, R 4$, and $R 5)$. The patients-resources assignments are given in Table I.

TABLE I. ASSIGNMENT PATIENT-RESOURCE

\begin{tabular}{|c|c|c|c|c|c|}
\cline { 2 - 6 } \multicolumn{1}{c|}{} & R1 & R2 & R3 & R4 & R5 \\
\hline P1 & 1 & 0 & 0 & 1 & 1 \\
\hline P2 & 1 & 1 & 1 & 0 & 1 \\
\hline P3 & 1 & 1 & 0 & 1 & 1 \\
\hline P4 & 1 & 0 & 1 & 1 & 0 \\
\hline P5 & 1 & 0 & 1 & 1 & 0 \\
\hline
\end{tabular}

The travel duration between each pair of home patients is given by the Table II.

Note 2: - The depot is the HHC structure.

TABLE II. DURATION OF TRAVEL(IN MINUTES)

\begin{tabular}{|c|c|c|c|c|c|c|}
\cline { 2 - 7 } \multicolumn{1}{c|}{} & Depot & P1 & P2 & P3 & P4 & P5 \\
\hline Depot & 0 & 21 & 15 & 36 & 42 & 9 \\
\hline P1 & 21 & 0 & 30 & 18 & 42 & 27 \\
\hline P2 & 15 & 30 & 0 & 12 & 15 & 39 \\
\hline P3 & 36 & 18 & 12 & 0 & 9 & 27 \\
\hline P4 & 42 & 42 & 15 & 9 & 0 & 30 \\
\hline P5 & 9 & 27 & 39 & 27 & 30 & 0 \\
\hline
\end{tabular}

The duration of care of the patient $i$ by the resource $k$ are given in the following table (table III).

TABLE III. DURATION OF CARE (IN MINUTES)

\begin{tabular}{|l|c|c|c|c|c|}
\cline { 2 - 6 } \multicolumn{1}{c|}{} & R1 & R2 & R3 & R4 & R5 \\
\hline P1 & 30 & 15 & 12 & 12 & 27 \\
\hline P2 & 15 & 12 & 18 & 15 & 12 \\
\hline P3 & 12 & 18 & 12 & 12 & 27 \\
\hline P4 & 18 & 12 & 27 & 15 & 12 \\
\hline P5 & 18 & 12 & 27 & 12 & 24 \\
\hline
\end{tabular}

Table IV report the time window data for patients and HHC structure.

TABLE IV. TIME WINDOWS

\begin{tabular}{|c|c|c|c|c|c|c|}
\cline { 2 - 7 } \multicolumn{1}{c|}{} & P1 & P2 & P3 & P4 & P5 & Depot \\
\hline b & $8: 00: 00$ & $8: 00: 00$ & $8: 00: 00$ & $8: 00: 00$ & $8: 00: 00$ & $8: 00: 00$ \\
\hline e & $16: 00: 00$ & $14: 00: 00$ & $18: 00: 00$ & $13: 00: 00$ & $12: 00: 00$ & $24 \mathrm{~h}+8 \mathrm{~h}$ \\
\hline
\end{tabular}

In table $\mathrm{V}$, we present the dates of unavailability of each patient and their durations, defined by the behavior of each patient. We assume in this example that the maximum number of unavailability doesn't exceed 2 .

TABLE V. DATE OF UNAVAILABILITY

\begin{tabular}{|c|c|c|c|c|c|}
\cline { 2 - 6 } \multicolumn{1}{c|}{} & P1 & P2 & P3 & P4 & P5 \\
\hline $\begin{array}{c}\text { Date of unavailability } \\
\mathbf{1}\end{array}$ & $9: 15: 00$ & $9: 00: 00$ & $8: 45: 00$ & $8: 15: 00$ & $8: 30: 00$ \\
\hline $\begin{array}{c}\text { Duration of } \\
\text { unavailability 1 }\end{array}$ & $21 \mathrm{mn}$ & $45 \mathrm{mn}$ & $30 \mathrm{mn}$ & $30 \mathrm{mn}$ & $15 \mathrm{mn}$ \\
\hline $\begin{array}{c}\text { Date of unavailability } \\
\mathbf{2}\end{array}$ & & & & & $9: 15: 00$ \\
\hline $\begin{array}{c}\text { Duration of } \\
\text { unavailability } 2\end{array}$ & & & & & $15 \mathrm{mn}$ \\
\hline
\end{tabular}


The obtained Results are reported in table VI. The first line presents the timetable of the resources departure from the HHC structure. While the last line gives the timetable of their comeback to the HHC structure. The other lines define the starting dates of cares for each patient.

TABLE VI. START DATE OF CARE

\begin{tabular}{|c|c|c|c|c|c|}
\cline { 2 - 6 } \multicolumn{1}{c|}{} & R1 & R2 & R3 & R4 & R5 \\
\hline Depot & $8: 00: 00$ & $8: 00: 00$ & $8: 00: 00$ & $8: 00: 00$ & $8: 00: 00$ \\
\hline P1 & $10: 24: 00$ & & & $9: 45: 00$ & $8.21: 00$ \\
\hline P2 & $8: 15: 00$ & $8: 30: 00$ & $10: 24: 00$ & & $10: 06: 00$ \\
\hline P3 & $9: 54: 00$ & $10: 09: 00$ & & $9: 15: 00$ & $9: 27: 00$ \\
\hline P4 & $9: 06: 00$ & & $9: 42: 00$ & $8: 51: 00$ & \\
\hline P5 & $9: 30: 00$ & & $8: 45: 00$ & $8: 09: 00$ & \\
\hline Depot & $11: 00: 00$ & $10: 42: 00$ & $11: 00: 00$ & $10: 03: 00$ & $10: 36: 00$ \\
\hline
\end{tabular}

This timetable is illustrated by Fig. 1 .

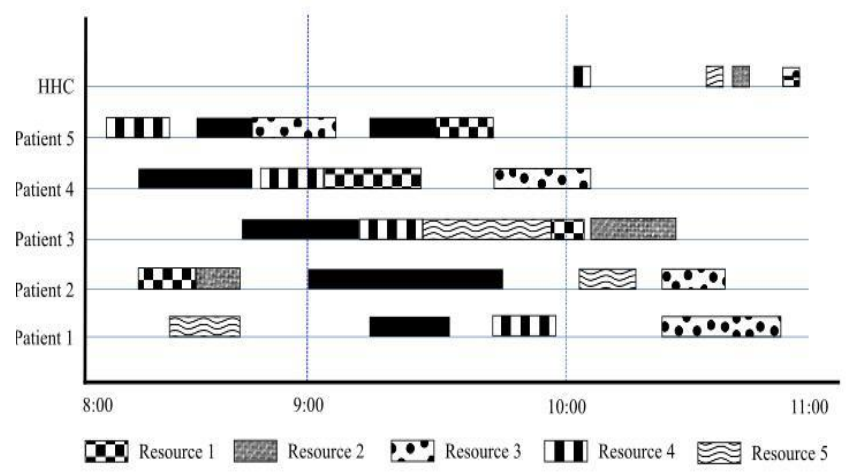

Fig. 1. Graphic timetable of the illustrative example.

These results show that resources respect the unavailability of patients. Moreover, all the resources start and end their day with the HHC structure and all the patients don't have a care synchronized (the resources do not arrive at the same time in the patient home).

In this diagram, the unavailability of patients is shown by black rectangles and the other rectangles shown the resources treatments duration at patient homes. For example, the tour of the resource 1 is; the depot then, patient 2, patient 4, patient 3, patient 1 , successively, and to finish filing the HHC structure. The visiting order in patient 2 is; Resource 1 then 2,5 and 3. These visits are divided in two phases, since resources 1 and 2 come before the period of unavailability and 5 and 3 after this period. Moreover, we can notice that resource 2 arrives at patient 2 at the end of the duration of treatment made by the resource 1 .

The data used for simulations are derived from studies of Elderly people behavior at GIS MADONAH of Bourges. It is assumed that the number of the resources is limited to 5, and the unavailability per patient is varying between 1-2.

The results are for instances with a number of parameters varying from 441 to 1941 (binary and integer variables) and a number of constraints varying from 1297 to 9025 constraints. All of these examples were solved to optimality in less than 6 seconds (see Table VII).

TABLE VII. RESULT OF TEST INSTANCES

\begin{tabular}{|c|c|c|c|c|c|c|c|c|}
\hline $\mathbf{N}$ & $\mathbf{A}$ & $\mathbf{R}$ & $\begin{array}{c}\text { Max } \\
\text { Assign }\end{array}$ & $\mathbf{U}$ & $\mathbf{C}$ & $\mathbf{V}$ & $\mathbf{C . P . U}$ & O.F. \\
\hline $\mathbf{1}$ & 5 & 5 & 1 & 1 & 1300 & 441 & 900 & 4.9 \\
\hline $\mathbf{2}$ & 5 & 5 & 1 & 2 & 1325 & 441 & 960 & 4.9 \\
\hline $\mathbf{3}$ & 5 & 5 & 2 & 1 & 1298 & 441 & 1370 & 5.85 \\
\hline $\mathbf{4}$ & 5 & 5 & 2 & 2 & 1323 & 4441 & 1400 & 5.9 \\
\hline $\mathbf{5}$ & 5 & 5 & 3 & 1 & 1297 & 441 & 1430 & 7.15 \\
\hline $\mathbf{6}$ & 5 & 5 & 3 & 2 & 1322 & 441 & 1140 & 7.4 \\
\hline $\mathbf{7}$ & 10 & 5 & 1 & 1 & 4250 & 1066 & 1420 & 8.15 \\
\hline $\mathbf{8}$ & 10 & 5 & 1 & 2 & 4300 & 1066 & 1150 & 8.15 \\
\hline $\mathbf{9}$ & 10 & 5 & 2 & 1 & 4248 & 1066 & 1140 & 9.25 \\
\hline $\mathbf{1 0}$ & 10 & 5 & 2 & 2 & 4298 & 1066 & 1600 & 9.25 \\
\hline $\mathbf{1 1}$ & 10 & 5 & 3 & 1 & 4247 & 1066 & 1570 & 9.6 \\
\hline $\mathbf{1 2}$ & 10 & 5 & 3 & 2 & 4297 & 1066 & 1670 & 9.6 \\
\hline $\mathbf{1 3}$ & 15 & 5 & 1 & 1 & 8950 & 1941 & 1850 & 9.8 \\
\hline $\mathbf{1 4}$ & 15 & 5 & 1 & 2 & 9025 & 1941 & 1670 & 9.8 \\
\hline $\mathbf{1 5}$ & 15 & 5 & 2 & 1 & 8948 & 1941 & 1140 & 10.8 \\
\hline $\mathbf{1 6}$ & 15 & 5 & 2 & 2 & 9023 & 1941 & 1840 & 10.85 \\
\hline $\mathbf{1 7}$ & 15 & 5 & 3 & 1 & 8947 & 1941 & 4810 & 10.9 \\
\hline $\mathbf{1 8}$ & 15 & 5 & 3 & 2 & 9022 & 1941 & 5460 & 10.95 \\
\hline & a. & $\begin{array}{l}\text { C.P.U. (Computational time to reach the optimal solution, given in milliseconds) } \\
\text { b. }\end{array}$ & C. (Number of constraints of the model) & & & \\
\hline & f. & V. (Number of variables of the model) & M.F. (The value of objective function) & & & \\
\hline
\end{tabular}

It is important to notice that the simulation time is increasing proportionally with the problem size. In fact, when the number of variables is 441 , the time of simulation is about $1140 \mathrm{~ms}$ and when the number of variables comes to 1941 , the time of simulation remains between 1140 and 5460ms. In other words, the complexity of the problem increases with the problem size. Nevertheless, all the considered problems were solved to optimality in few seconds, which shows the efficiency of the model and the choice of the approach used to solve it.

\section{CONCLUSION AND PERSPECTIVES}

In this paper we have presented a mixed integer linear programming model for solving a daily resources planning problem among home patients (HHC problem). This MILP model was implemented using a commercial software IlogCplex of IBM, and a large set of numerical experiments was carried out for a set of real-data. The obtained results show the effectiveness of the proposed approach.

For future research, several extensions of this MILP model have to be considered, such as the inclusion of resources 
behavior and resources synchronization constraints in addition to the aspect of uncertainty due to unexpected events.

\section{ACKNOWLEDGMENT}

This research was supported in part by the engineering school "Ecole Centrale de Lille (EC-Lille)" under a grant from the ANR Research Project, named "Performing Enhanced Railway Formal Engineering Constraints Traceability (PERFECT)".

\section{REFERENCES}

[1] Kacem I., Farrokhi V., Pokorádi L., Classement des techniques de solution pour le problème d'ordonnancement réactif dans la salle d'opération, Contrôle, décision et Technologies de l'Information (CODIT), IEEE, 001-006, 2014.

[2] Ajmi I., Zoghlami N., Benoit Y., Chandoul W., Kaddoussi A., Hammadi S., Système d'Aide à la Gestion et à l'Anticipation de la Tension dans les Hôpitaux, https://hal.archives-ouvertes.fr/hal00790759, 2013.

[3] Redjem R., Aide à la décision pour la planification des activités et des ressources humaines en hospitalisation à domicile, Université Jean Monnet - Saint-Etienne, https://tel.archives-ouvertes.fr/tel-00999994, 2013.

[4] Bashir B., Caux C., Litérature review in Home Care, 9th International Conference of Modelling and Simulation (MOSIM), 2012.

[5] Gayraud F., Derrousi L., Grangeon N., Norre S., A new mathematical formulation for the home health care problem, Procedia Technology, 9,1041-1047, 2013.

[6] De Angelis V., Planning Home Assistance for AIDS Patients in the City of Rome, Italy, Institute of operations research and the management science 28, 75-83, 1998.

[7] Lahrichi N., Analysis of a territorial approach to the delivery of nursing home care services based on historical data. Journal of Medical Systems, 30, 283-291, 2004.

[8] Blais M., Lapierre S.D., Laporte G., Solving a Home-Care Districting Problem in an Urban Setting. The Journal of the Operational Research Society, 54, 1141-1147, 2003.

[9] Begur S. V., Miller D. M., and Weaver J. R., An Integrated Spatial DSS for Scheduling and Routing Home-Health-Care Nurses. Interfaces, volume (27), 35-48, 1997.

[10] Eveborn P., Flisberg P. \& Rönnqvist M., Laps Care--an operational system for staff planning of home care. European Journal of Operational Research, 171(3), 962-976, 2006.

[11] Bertels S. and Fahle T., A hybrid setup for a hybrid scenario: combining heuristics for the home health care problem. Computers \& Operations Research, 33(10), 2866-2890, 2006.

[12] Borsani V., Matta Beschi G., Sommaruga F., Home care scheduling model for human resources, International Conference on Service Systems and Service Management, volume (1), 449-454, 2006.

[13] Thomson K., Optimization on home care, Thèse de doctorat, Informatics and Mathematical Modelling, Technical University of Denmark, DTU, 2006.
[14] Akjiratikarl C., Yenradee P., Drake P.R., PSO-based algorithm for home care worker scheduling in the UK. Computers \& Industrial Engineering, 53(4), 559-583, 2007.

[15] Chahed J.S, Dalery Y., and Evren S., « Modélisation et analyse de l'organisation et du fonctionnement des structures d'hospitalisation à domicile ». Multidisciplinary thesis server, 2008.

[16] Steeg, J. \& Schröder, M., A Hybrid Approach to Solve the Periodic Home Health Care Problem. Dans Operations Research Proceedings 2007. p. 297-302. Available at: http://dx.doi.org/10.1007/9783-54077903-2_46, 2008.

[17] B. Bachouch, R. Fakhfakh, M. Guinet, A. et Gabouj, S. H. Planification des tournées des infirmiers dans une structure de soins à domicile. Gestion et Ingénierie des Systèmes Hospitaliers, volume (8), 3-5, 2009.

[18] Bräysy, O. An optimization approach for communal home meal delivery service: A case study. Journal of Computational and Applied Mathematics, 232(1), 46-53, 2009.

[19] Redjem R., Kharraja S., Marcon E., Xie X., ordonnancement des activités en HAD avec prise en compte de la coordination des soins, J D Macs journées Doctorales Macs, Marseille (France), 2011.

[20] Redjem R., Aide à la décision pour la planification des activités et des ressources humaines en hospitalisation à domicile, Université Jean Monnet - Saint-Etienne, https://tel.archives-ouvertes.fr/tel-00999994, 2013.

[21] Gayraud F., Derrousi L., Grangeon N., Norre S., A new mathematical formulation for the home health care problem, Procedia Technology, 9,1041-1047,2013.

[22] liu R., Xie X., Augusto V., Rodriguez C., Heuristic algorithms for a vehicle routing problem with simultaneous delivery and pickup and time windows in home health care, European Journal of Operational Research, 230, 475-486, 2013.

[23] Cappanera, P., Scutellà, M.G. Joint assignment,scheduling and routing models to home care optimization: a pattern based approach, University DI PISA, Technical Report : TR-13-05, 2013.

[24] Thie Viet Ly, N., Montemanni, R. Scheduling and routing in home health care service. Proceeding of the finish Operations Research Society $40^{\text {th }}$ Anniversary Workshop-FORS40, Lappeenranta 20, 2013.

[25] Issaoui B., Zidi I., Marcon E., Ghedira K., new multi-objective approach for the home care service problem based on scheduling algorithms and variables neighborhood descent, Electronic Notes in Discrete Mathematics, 47, 181-188, 2015.

[26] Lanzarone E., Carello G., A cardinality-constrained robust model for the assignment problem in home care services, European journal of Operational Research, 236, 748-762, 2014.

[27] En Nahli, L., Nouaouri, I., Allaoui, H. La planification quotienne dans une structure d'hospitalisation à domicile avec prise en considération du facteur humain. (MOSIM'14), Nancy (France), 2014.

[28] Koeleman P.M., Bhulai S., Van Meersbergen M., optimal patient and personnel schedulling policies for care-at-home service facilities, European Journal of Operational Reseach, 219, 557-563, 2012.

[29] Lanzarone E., Matta A., Sahin E., Operations management applied to home care services: The problem of assigning human resources to patients, IEEE Transactions on Systems, Man and cybernetics. Part A : Systems and humans, 42(6), 1346-1363, 2012.

[30] Council directive on Hospital Care at Home: http://www.fnehad.fr/quest-ce-que-lhad/ 